\title{
Implementação de ferramenta para a organização do fluxo dos usuários na rede pública de reabilitação: inovar para aumentar a efetividade
}

Pollyana Ruggio Tristão Borges, Sheyla Rossana Cavalcanti Furtado, Mariana Angélica Peixoto de Souza, Fabiane Ribeiro Ferreira, Rosana Ferreira Sampaio

\section{Resumo}

O Sistema Único de Saúde organiza seus serviços de forma integrada e em diferentes níveis de complexidade, nas chamadas Redes de Atenção à Saúde, dentre elas, a rede de reabilitação. A falta de sistematização na abordagem do usuário, na coleta e registro de informações pode impedir o adequado planejamento das ações. Visando sistematizar a coleta de informações funcionais no acolhimento do usuário pela rede de reabilitação, foi criado o Protocolo de Levantamento de Problemas para a Reabilitação (PLPR). O PLPR possui questões que representam os componentes da Classificação Internacional de Funcionalidade, Incapacidade e Saúde, possibilitando a caracterização social, da saúde e Breve Descrição Funcional (BDF). Na BDF há 25 itens, distribuídas em 10 domínios: Mobilidade, Comunicação, Eutrofia, Auto-cuidado, Dor, Atividade Interpessoal, Energia e Sono, Afeto, Tarefas e Demandas Gerais, Trabalho Remunerado, cuja interpretação pode ser apresentada em escores por domínios ou total (eBDF). Descrever os escores total e por domínios da BDF do PLPR e relacioná-los com as informações sociais e de saúde dos usuários, bem como com o resultado final do protocolo quanto ao local de atendimento, profissionais envolvidos e demandas principais. A amostra foi composta por 683 usuários acolhidos na rede pública de reabilitação de Belo Horizonte, entre 2012 e 2014. Foram realizadas análises descritivas, e utilizado o teste t para comparar as médias eBDF de acordo com as características dos usuários e resultado do PLPR. Os usuários tinham em média 57 anos, 74\% eram mulheres, 46\% casados/união estável. Mais da metade tinham até o ensino fundamental incompleto ou não eram alfabetizados (52\%) e $46 \%$ estavam ativos no mercado de trabalho. Sedentarismo (65\%) e sobrepeso (29\%) foram os principais fatores de risco. Quanto à percepção da saúde, 41\% consideraram a saúde física Moderada e $44 \%$ a saúde emocional Muito boa/Boa. Sensação de dor foi o item da BDF que mais apresentou dificuldade grave ou completa pelos usuários (59,7\%), seguido por Funções relacionadas à mobilidade das articulações $(48,3 \%)$. A média do eBDF foi 27,54. Na análise por domínios, Dor e Desconforto foi o que apresentou média mais alta $(6,10$; $\mathrm{DP}=3,01)$, seguido por Mobilidade $(3,59 ; \mathrm{DP}=3,47)$. A maioria dos usuários iniciou a reabilitação na Atenção Básica $(83 \%)$ e demandou o acompanhamento por apenas um profissional da reabilitação $(76 \%)$. A análise das médias do eBDF revelou que os usuários: do sexo feminino, que iniciaram a reabilitação na Atenção Especializada, não alfabetizados, com percepção da saúde física e emocional ruim/muito ruim, com menos de 60 anos de idade, sedentários, com sobrepeso e tabagistas apresentaram maior média no eBDF, indicando pior funcionalidade $(\mathrm{p}<0,05)$. Espera-se, que a aplicação e informatização do PLPR na rede pública de reabilitação contribuam para o planejamento e organização dos serviços, a partir da análise da demanda funcional dos usuários.

Descritores: Acolhimento; Classificação Internacional de Funcionalidade, Incapacidade e Saúde; Sistema Único de Saúde. 